\title{
Detection of snowmelt regions on the Greenland ice sheet using diurnal backscatter change
}

\author{
S.V. Nghiem, ${ }^{1}$ K. Steffen, ${ }^{2}$ R. Kwok, ${ }^{1}$ W.-Y. Tsai ${ }^{1}$ \\ ${ }^{1}$ Fet Propulsion Laboratory, California Institute of Technology Pasadena, 4800 Oak Drive, California 91109-8099, U.S.A. \\ ${ }^{2}$ Cooperative Institute for Research in Environmental Sciences, University of Colorado, Boulder, Colorado 80309-0449, U.S.A.
}

\begin{abstract}
Snowmelt regions on Greenland ice are mapped daily with the SeaWinds wideswath Ku-band $(13.4 \mathrm{GHz})$ scatterometer on the QuikSCAT satellite. The approach exploits the high temporal resolution of SeaWinds/QuikSCAT data for the melt mapping using diurnal backscatter change independent of the absolute calibration. The results reveal several pronounced melting and refreezing events, and effects of topography are evident in the melt patterns. The spatial resolution is sufficient to identify melt features on the Sukkertoppen Iskappe west of the main ice sheet. An anomalous warming event, caused by downward mixing of warm air, is detected in late September 1999 over the west flank of the southern Greenland ice sheet. Time-series images of melt regions are presented over the period from summer to the fall freeze-up. The satellite observations are verified with in situ measurements from the Greenland Climate Network stations.
\end{abstract}

\section{INTRODUGTION}

The vast Greenland ice sheet plays an important role in regional and global climate (Konzelmann and Ohmura, 1995), and is an important component of the global hydrologic balance (Ohmura and others, 1996). The shortwave incoming radiative flux absorbed by the snowpack can increase significantly due to small changes in snow albedo, in particular for a change from a dry- to a melting-snow surface (Stroeve and others, 1997). Because the average slope of the ice sheet is $<1^{\circ}$, small changes in air temperature can result in large areal changes of dry- and wet-snow facies (Abdalati and Steffen, 1995). The Greenland ice sheet is thus a sensitive indicator of climate variability, as demonstrated by the observed reduction in the melt area after the eruption of Mount Pinatubo, Philippines (Abdalati and Steffen, 1997).

Classification of Greenland snowmelt regions has been investigated with different satellite datasets. With radiometer data from the Special Sensor Microwave/ Imager (SSM/I), Mote and others (1993) used a singlechannel threshold method, Steffen and others (1993) applied the horizontally polarized gradient ratio technique, and Abdalati and Steffen (1995) employed the crosspolarized gradient ratio approach. C-band synthetic aperture radar (SAR) data have been used to classify different snow facies, including dry- and wet-snow zones, on Greenland ice (Drewry and others, 1991; Fahnestock and others, 1993; Jezek and others, 1993; Partington, 1998). Absolute backscatter data from Ku-band scatterometers such as Seasat-A Satellite Scatterometer (SASS) and NASA Scatterometer (NSCAT) are also used to map Greenland melt areas with an imaging period of 2 weeks (Long and Drinkwater, 1999).

In this paper, we delineate melt regions on the Greenland ice sheet using relative backscatter from daytime and night- time satellite overpasses of the current SeaWinds scatterometer on the QuikSCAT satellite. Advantages of the melt mapping using SeaWinds/QuikSCATdata include:

(a) high temporal coverage of the whole of Greenland twice per day due to the very wide swath of the sensor,

(b) high sensitivity of Ku-band backscatter to snow wetness with a dynamic range of more than one order of magnitude,

(c) use of relative backscatter independent of the absolute calibration,

(d) detection of both melt and freeze-up of the snow,

(e) verification of satellite results with in situ data from the Greenland Climate Network (GC-Net) stations, strategically located over different melt regions.

Our approach does not depend on the absolute backscatter and is independent of the long-term drift of the scatterometer gain. This allows consistent interannual monitoring of melt regions, while the high temporal resolution makes possible observations of weather events on a daily time-scale.

\section{SATELLITE AND FIELD DATA}

The QuikSCAT satellite was successfully launched on 19 June 1999. The satellite carries the SeaWinds scatterometer for ocean wind measurements (Tsai and others, 2000). The scatterometer has been collecting data at $13.4 \mathrm{GHz}$ (wavelength $22.4 \mathrm{~mm}$ ) on both ocean and land. Backscatter data, at a radiometric resolution of $7 \mathrm{~km} \times 25 \mathrm{~km}$, are acquired with the vertical polarization $\left(\sigma_{\mathrm{VV}}\right)$ at a constant incidence angle of $54^{\circ}$ over a conical-scanning swath of $1800 \mathrm{~km}$, and with the horizontal polarization $\left(\sigma_{\mathrm{HH}}\right)$ at $46^{\circ}$ over a $1400 \mathrm{~km}$ swath.

Due to the very wide swath, we select vertical-polarization data which cover the entire Greenland ice sheet twice 


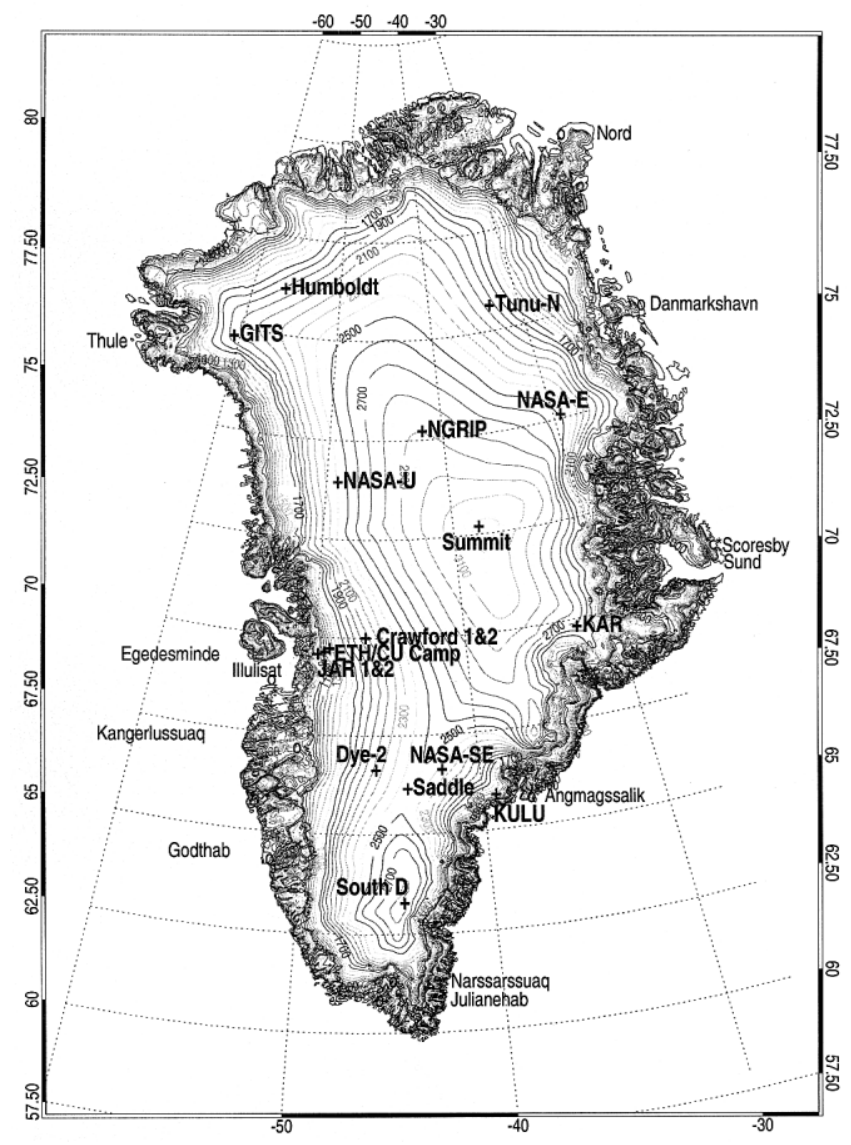

Fig. 1. Locations of GC-Net stations on the topographic map.

per day. The two local overpass times are around 6:20 and are approximately $12 \mathrm{~h}$ apart in a sun-synchronous orbit. The satellite orbit was stabilized, the scatterometer performance was verified, and the calibrated science data have been acquired since 19 July 1999. At that time, melt had occurred on the Greenland ice sheet, presenting the first opportunity to study diurnal variations of melt regions with the new dataset.

In conjunction with the satellite data, we use hourly in situ measurements including air temperature, net radiation, shortwave solar radiation and wind speed. The field data are acquired at meteorological stations of the Program for Arctic Regional Climate Assessment (PARCA) GG-Net (Steffen and Box, in press). Figure 1 shows the locations of GC-Net stations on the Greenland topographic map. In particular, stations $\mathrm{ETH} / \mathrm{CU}\left(69.569^{\circ} \mathrm{N}, 49.311^{\circ} \mathrm{W}\right.$; also called Swiss Camp) and Crawford Point $1\left(69.882^{\circ} \mathrm{N}, 46.974^{\circ} \mathrm{W}\right)$, Dye-2 $\left(66.481^{\circ} \mathrm{N}\right.$, $\left.46.280^{\circ} \mathrm{W}\right)$, South Dome $\left(63.149^{\circ} \mathrm{N}, 44.817^{\circ} \mathrm{W}\right)$ and KAR $\left(69.700^{\circ} \mathrm{N}, 33.000^{\circ} \mathrm{W}\right)$ are strategically located in the west, central, south and east regions, respectively, where snowmelt typically occurs. Stations Saddle and NASA-SE would have provided additional data; however, both stations stopped transmitting via the satellite link in spring 1999, and the data will be available after the on-site visit in summer 2001.

\section{METHODOLOGY}

\subsection{Melt energy and snow wetness}

The energy required for melting, $M$, is provided by the surface energy balance given by the following equation:

$$
M=R_{\mathrm{T}}+\left(F_{\mathrm{H}}-F_{\mathrm{C}}\right)+A,
$$

where the total net radiation flux $R_{\mathrm{T}}=R_{\mathrm{S}}+R_{\mathrm{L}}$ includes the net shortwave $\left(R_{\mathrm{S}}\right)$ and the net longwave $\left(R_{\mathrm{L}}\right)$ radi- ation fluxes, the heat flux $F_{\mathrm{H}}=F_{\mathrm{S}}+F_{\mathrm{L}}$ consists of the sensible- $\left(F_{\mathrm{S}}\right)$ and the latent-heat $\left(F_{\mathrm{L}}\right)$ fluxes, $F_{\mathrm{C}}$ is the conductive-heat flux, and $A$ is an unknown source of energy or an error term (Braithwaite and others, 1998). There is usually a strong diurnal variation in the melt energy (Braithwaite and others, 1998) because the main contributor is incoming shortwave (solar) radiation and to a lesser extent the sensible-heat flux, the turbulent flux of heat from warm air to the colder surface (Steffen, 1995).

Melting or refreezing results in a difference $\Delta m_{\mathrm{v}}=$ $m_{\mathrm{v}}\left(t_{\mathrm{p}}\right)-m_{\mathrm{v}}\left(t_{\mathrm{a}}\right)$ in snow wetness $m_{\mathrm{v}}$ at different overpasses of the satellite $\left(t_{\mathrm{p}}\right.$ is for descending overpasses in late afternoon and $t_{\mathrm{a}}$ for ascending overpasses in early morning). We call a region with $\left|\Delta m_{\mathrm{v}}\right|>W$ a melt/refreezing region, where $W$ is a positive number (see section 3.4). The implication is that $m_{\mathrm{v}}\left(t_{\mathrm{p}}\right)$ and $m_{\mathrm{v}}\left(t_{\mathrm{a}}\right)$ are non-zero, or either one can be zero but not both. Thus, according to this definition, there must be some liquid water in snow at some time, but not necessarily all the time, in a given day for the region to be classified as a melt region for that day. In this context, the term "refreezing" includes total refreezing for dry snow $\left(m_{\mathrm{v}}=0\right)$ and also partial refreezing when some liquid water may still exist in snow $\left(m_{\mathrm{v}} \neq 0\right)$. A good proxy value to detect surface melt is the near-surface air temperature that is available from the GC-Net automatic weather stations (Steffen and Box, in press). We describe the detection of melt/refreezing regions SeaWinds/QuikSCAT data in the following subsections. The determination of the absolute energy balance of the surface is not within the scope of this paper.

\subsection{Backscatter signature of snowmelt}

The principle of the melt-region delineation is based on the high sensitivity of backscatter at Ku-band frequencies to wetness in the snow cover. Ku-band backscatter of Greenland snow comes from subsurface volume scatterers located within different snow and ice structures. In fact, groundbased radar measurements of dry snow at Crawford Point indicate that the backscatter can be dominated by subsurface depth hoar and coarse-grain firn (Jezek and others, 1994). When the wetness in the snow surface layer increases, $\mathrm{Ku}$-band wave energy is absorbed and subsurface scatterers are masked, resulting in a large decrease in backscatter.

$\mathrm{Ku}$-band backscatter change is very sensitive to snow wetness (Stiles and Ulaby, 1980). At 50 incidence angle, snow backscatter can change by $6-10 \mathrm{~dB}$ (a factor of more than 4 times to one order of magnitude) between the cases with different snow wetness and snow depth (Stiles and Ulaby, 1980). Figure 2 illustrates the sensitivity of snow backscatter to wetness. Ku-band backscatter is calculated from a physical snow-scattering model (Nghiem and others, 1995) for the vertical polarization at $56^{\circ}$ incidence angle (SeaWinds scatterometer configuration). The calculated results also show $>10 \mathrm{~dB}$ change from $0 \%$ to $5 \%$ volumetric snow wetness. For a given amount of change in wetness, the backscatter change is larger at the lower range of wetness values, as seen in Figure 2. We do not have in situ observations of volumetric wetness of snow measured at the same time and at the same place with QuikSCAT data used in this paper. However, a few per cent or more of volumetric wetness in the surface snow layer is typical for snowmelt in Greenland (Denoth, 1985; Mote and Rowe, 1996).

The above measured and model results indicate that backscatter in the $\mathrm{Ku}$ band is very sensitive to wetness in 


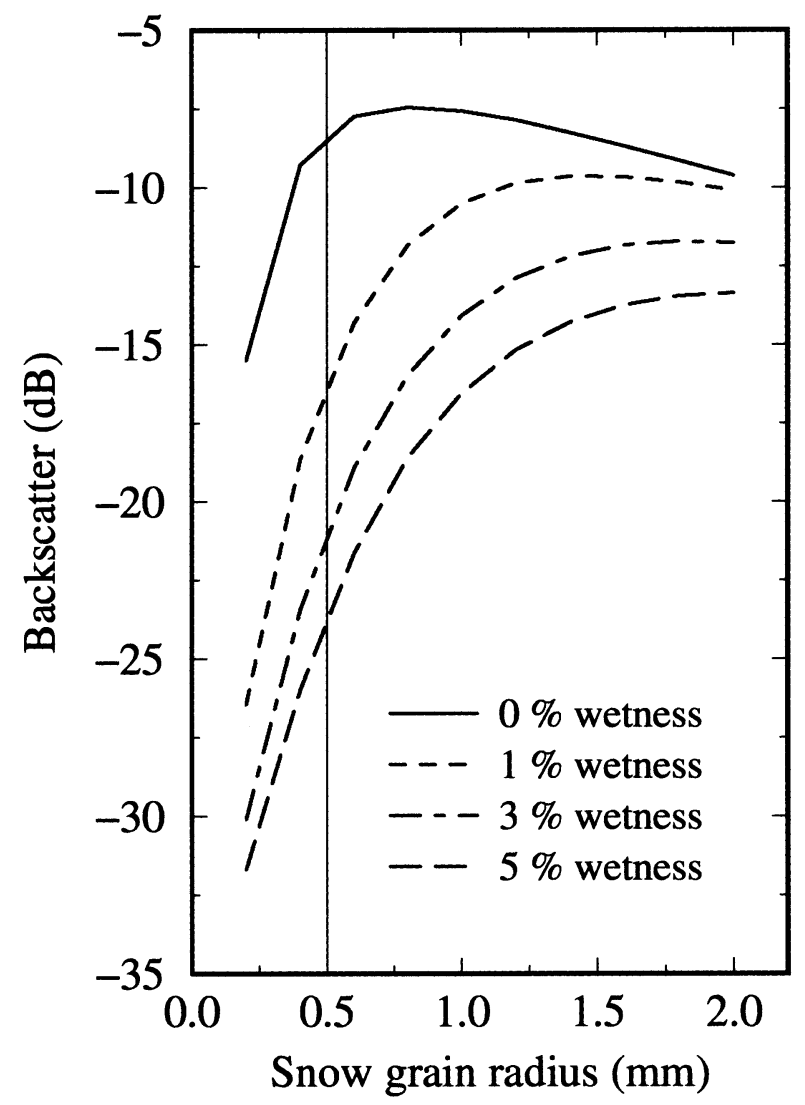

Fig. 2. Ku-band backscatter $W$ at $54^{\circ}$ for different snow wetness.

near-surface layers because backscattering from deep layers is masked by the upper layers. Once the wetness in the surface layers is reduced or frozen out, the backscatter increases because the loss is reduced significantly (Nghiem and others, 1995) and backscatter by ice grains in snow is very strong at $\mathrm{Ku}$ band due to the Rayleigh scattering (Nghiem and Tsai, 2001). While a larger wetness from former melt events may exist in the deeper layers during the refreezing process, strong scattering from the upper layers will dominate the total backscatter and overwhelm any effect from deeper layers.

Other factors influencing backscatter can be the dependence of ice permittivity on temperature and changes in surface roughness. However, the temperature dependence of ice permittivity is weak (Vant and others, 1978; Tiuri and others, 1984), and the snow surface roughness effect is small (Tsang and others, 1985) at the large incidence angle of SeaWinds/QuikSCATdata used in this paper. For a given pixel at the $25 \mathrm{~km}$ resolution scale, backscatter data obtained in ascending and descending orbits at different azimuth angles can have slightly different local incidence angles due to the non-zero slope of the local topography. However, effects of the difference in the local incidence angles are small because backscatter of both dry and wet snow is a weak function of incidence angle (Stiles and Ulaby, 1980) around the SeaWinds/QuikSCAT incidence angle.

\subsection{Approach}

To delineate melt regions on the Greenland ice sheet, we exploit the relative difference in SeaWinds diurnal backscatter data. Because of the large swath, the entire Greenland ice sheet is measured in the early morning and again in the late afternoon. We subtract co-located data in the decibel scale, between the early morning and late afternoon coverages with a resolution of $25 \mathrm{~km}$. Because the $\mathrm{dB}$ scale is logarithmic, the subtraction in the $\mathrm{dB}$ scale is equivalent to taking the ratio in the linear scale.

To utilize the entire swath of the scatterometer, the approach requires that the incidence angle is constant over the whole swath because backscatter is a function of incidence angle. Thanks to the conical scanning configuration of the SeaWinds scatterometer, the incidence angle of $\sigma_{\mathrm{VV}}$ is fixed at $54^{\circ}$. Therefore, it is not necessary to have exact repeats of the orbit to obtain data consistently at the same incidence angle. Unlike NSCAT with variable incidence angles (Nghiem and Tsai, 2001), the constant incidence angle of the SeaWinds scatterometer enables the use of its very large wideswath, which makes possible the diurnal coverages required in our approach.

In the late afternoon, snow could have melted due to solar radiation and thermal effects throughout the day. In the early morning, snow could have refrozen throughout the previous night. This approach considers the backscatter difference between the two overpass times. Note that backscatter is also a function of grain-size as shown in Figure 2. In the refreezing process, snow grains can coalesce and the effective size increases while wetness decreases. These changes thus enhance the ability of the relative backscatter approach to detect a region where refreezing has occurred.

Another advantage of the method is that it is sensitive only to the region on the Greenland ice sheet with snow cover. Over bare land such as the barren coastal zone of Greenland, backscatter is not as sensitive to diurnal changes, and the method will classify the bare land as unchanged. The method will not detect melting when an area becomes saturated with meltwater during both daytime and night-time, where the diurnal backscatter change is weak and the area is classified with the green color. This is also the case for continuously melting bare ice. Another case is $M=0$ such that there is no change in snow wetness between day and night. However, this case is not likely to occur often over a large area, as it represents a situation where there is no diurnal change in the melt energy.

\subsection{Sign of wetness change}

We define the diurnal backscatter change as the backscatter difference given by

$$
\Delta \sigma_{\mathrm{VV}}=\sigma_{\mathrm{VV}}\left(t_{\mathrm{p}}\right)-\sigma_{\mathrm{VV}}\left(t_{\mathrm{a}}\right)
$$

where all backscatter values are given in the $\mathrm{dB}$ scale. Since a larger wetness corresponds to a lower backscatter value, $\Delta \sigma_{\mathrm{VV}}$ has the opposite sign to $\Delta m_{\mathrm{v}}$. For a backscatter change more than $1.8 \mathrm{~dB}$, corresponding to the lower end of backscatter change in Figure 2, we classify the pixel to be in an active melt/refreezing region. While a transition between dry and wet conditions renders a large backscatter change as indicated in Figure 2, it is not necessary for the snow cover to switch from dry to wet condition for the melt region to be identified. The melt region can be delineated as long as there is a difference in wetness caused by either melting or refreezing.

For a positive backscatter change less than $1.8 \mathrm{~dB}$ and a negative change higher than $-1.8 \mathrm{~dB}\left(\left|\Delta \sigma_{\mathrm{VV}}\right|<1.8 \mathrm{~dB}\right)$, we classify the region with a green color. This typically indicates the condition in the dry-snow zone of the ice sheet. We assign a blue color to areas where $\Delta \sigma_{\mathrm{VV}}<0$, representing the case of wetter snow in the afternoon than in the morning. Inversely, we use a red color for positive $\Delta \sigma_{\mathrm{VV}}$ as an indicator of wetter 

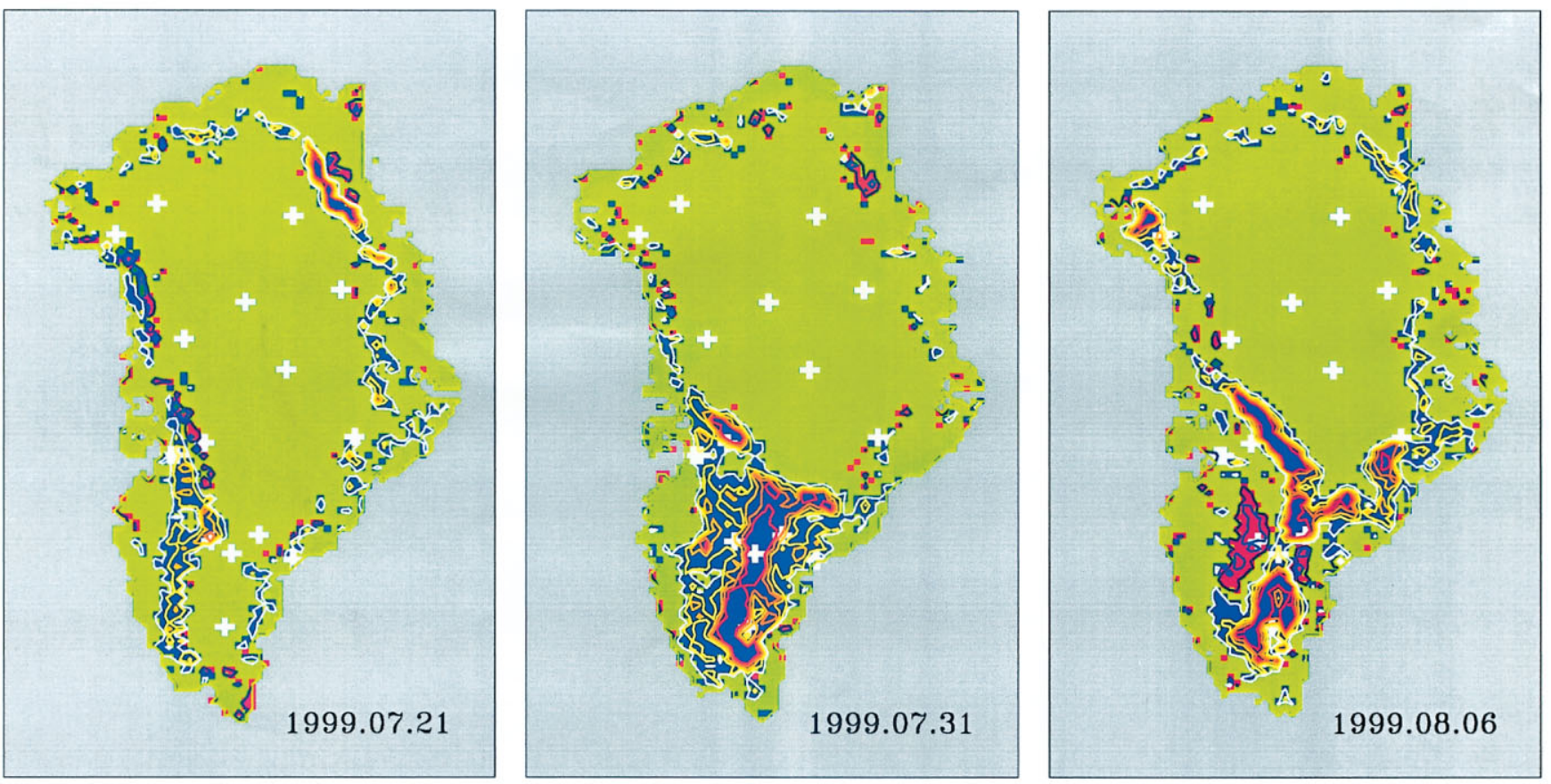

Fig. 3. Images of melt regions on the Greenland ice sheet in Fuly and August 1999. Over the blue regions, five contour levels for 2$10 \mathrm{~dB}$ backscatter change with $2 \mathrm{~dB}$ increments are denoted in white, yellow, light orange, dark orange and red, respectively. Over the red regions, five contour levels for 2-10 dB backscatter change are denoted in dark blue, light blue, dark green, green and light green, respectively. The locations of GC-Net stations are marked with the white'+'on the maps.

snow in the morning. Over a melt region delineated with either a blue or red color, we overlay contour lines for the backscatter change to indicate the intensity of the change. Note that the dependency on grain-size (Fig. 2) does not allow for estimates of absolute wetness change. The contours are merely used to study the relationship with geophysical characteristics of the Greenland ice sheet.

\section{RESULTS}

\subsection{Summer melt patterns}

We first study three cases at different times during the 1999 summer melt period. The results are presented in Figure 3 for satellite observations, and in Figure 4 for in situ temperature measurements from four GG-Net stations including Dye-2 in the center, South Dome in the south, Crawford Point 1 in the west and KAR in the east. The three images in Figure 3 show melt regions in late July (21 July 1999), at the end of July (31 July 1999) and in early August (6 August 1999). GC-Net temperature data are plotted in Figure 4, and the dates of the three cases are indicated with the three vertical bands in the temperature plots, where the horizontal axis is marked with ticks at the beginning of the dates.

The results reveal both areal extent and intensity of the melt. In late July (21 July 1999), an extensive melt band appeared along the west side of Greenland, and another smaller melt band occurred along the northeast side. There was no significant melt observed at the locations of the four stations, except that Dye-2 was at about the edge of the melt region. These observations agree well with the temperature data in Figure 4, showing air temperatures well below freezing, except Dye-2 temperature came up to within just a degree below zero on 21 July. The contour in the left map for 21 July 1999 in Figure 3 indicates a very small area with a strong backscatter change $(8 \mathrm{~dB})$ in the northern vicinity of Dye-2.

At the end of July (31 July 1999), the melt region was wide- spread in southern Greenland while the northeast melt band had shrunk to a small area, as seen in the middle map in Figure 3. Both Crawford Point 1 and Dye-2 were well within the blue melt region, indicating that snow wetness in the morning was lower than in the afternoon. In situ temperatures at the two stations (Fig. 4a for Dye-2 and Fig. 4c for Crawford Point 1) indeed show a diurnal warming cycle from freezing conditions in the morning to positive temperatures in the afternoon. The field-station data verify SeaWinds scatterometer results that (a) melting occurred at those locations, and (b) there was wetter snow in the afternoon. The net radiation at Dye-2 peaked at $116 \mathrm{~W} \mathrm{~m}^{-2}$, an indication of overcast sky conditions, which was even higher than on the previous day when the temperature had exceeded zero. At South Dome, the contours show minimal wetness, in agreement with the low temperature there (see Fig. 4b). At KAR in the east, there was no melt observed by the satellite scatterometer, in agreement with the low temperature measured at the station (see Fig. 4d).

In early August (6 August 1999), melt areas were still extensive in southern Greenland, as observed in the right map in Figure 3; however, this melt region became fragmented compared to the case at the end of July. A large melt band extended in the northwest-southeast direction along the higher side passing Crawford Point 1; unfortunately the station data were not available. In contrast to the end-of-July case, Dye-2 station was located within the "red" melt area, indicating a higher level of melt energy in the morning. This observation is verified with temperature data at Dye-2, showing higher positive temperatures in the morning, as seen in the in situ data plot in Figure 4a. The contours in the map for 6 August 1999 in Figure 3 suggests some melting around, but excluding, South Dome station. Over the east side, the edge of the melt region extended up to the south of KAR station. In situ temperatures at both stations were approaching $-1{ }^{\circ} \mathrm{C}$ close to the melting condition as seen in Figure $4 \mathrm{~b}$ and d. 

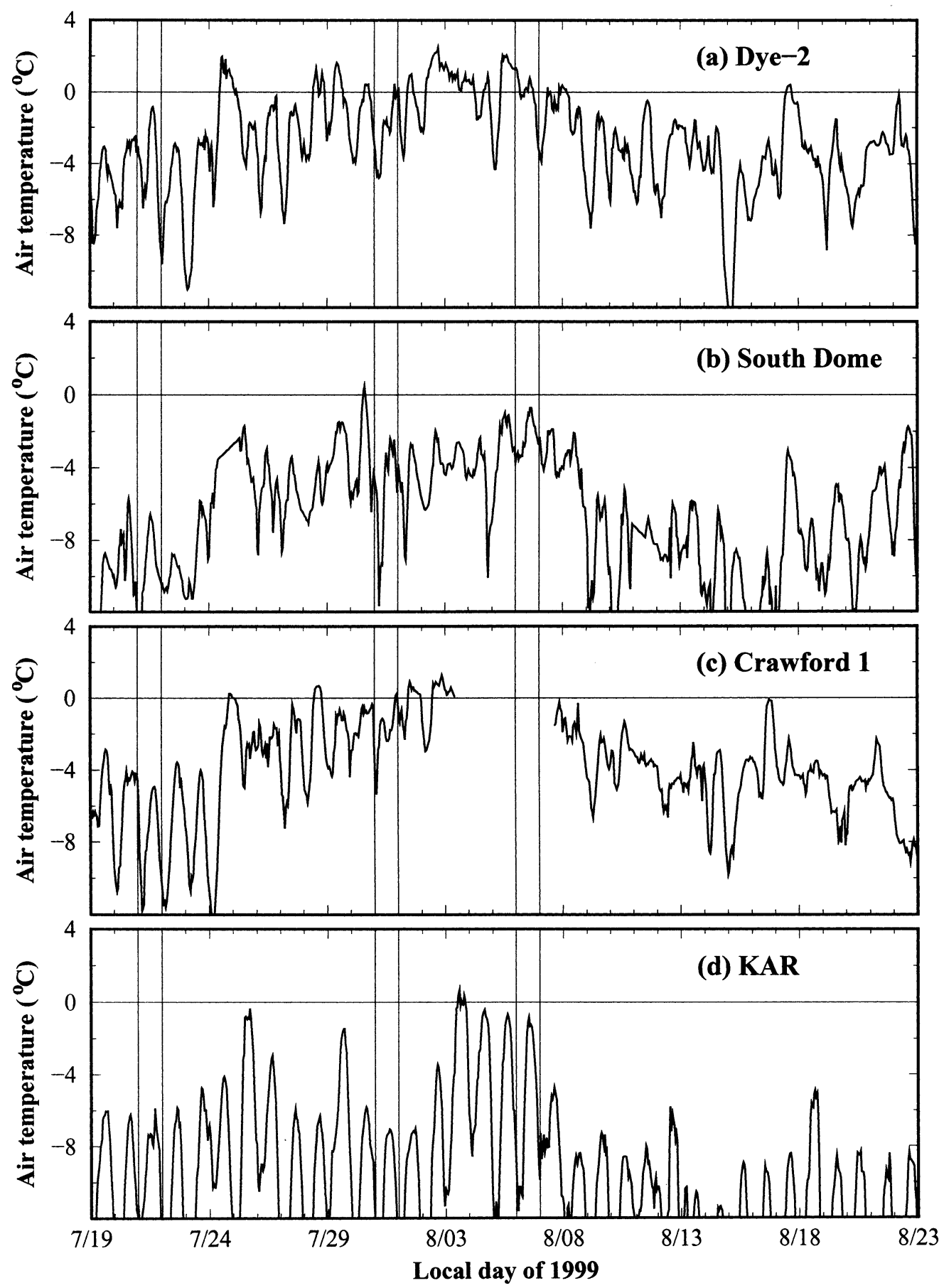

Fig. 4. Air temperatures measured at GC-Net stations: (a) Dye-2, (b) South Dome, (c) Crawford Point 1 and (d) KAR.

Figure 3 reveals melt patterns related to the geo-location and topographic characteristics of Greenland. The west coastal region, along the western melt band on 21 July 1999, appears in green in the corresponding map because of the snow-free coastal land. The red contours in the middle map of Figure 3 show backscatter changes of $10 \mathrm{~dB}$ or larger around South Dome, passing Saddle and extending to the north of Saddle. As discussed above, the backscatter change can be $>10 \mathrm{~dB}$, and the larger change corresponds to the lower range of wetness value. In this respect, the melt pattern on 31 July 1999 indicates a lower wetness distribution over areas coincident with higher altitudes, as seen in the topography presented in Figure 1.

The relationship between the pattern of melt regions and the topography is also revealed in the right map in Figure 3. The melt pattern exhibits four separated regions extended from Saddle station. The two melt regions in the north and south of Saddle are classified in blue, with strong backscatter changes corresponding to wetness lower in the morning over the higher elevations (see topography in Fig. 1). The other two melt regions to the west and east of Saddle station appear in red, with smaller backscatter changes for wetness higher in the morning over the lower elevations of those areas. Another feature that shows the close relation between the pattern of melt distribution and the topography is the green area (boomerang-shaped) in the southwest below KAR station.

We have derived daily maps of melt regions from the summer well into the fall until early November 1999. The time series includes more than 100 maps, from which we select representative results to present the seasonal variations of melt regions on the ice sheet in Figure 5. The time-series results show extensive melt in July and August from the west to the east of southern Greenland, with the largest melt areal extent in late July and early August. Later in August, the melt regions are more limited toward the 

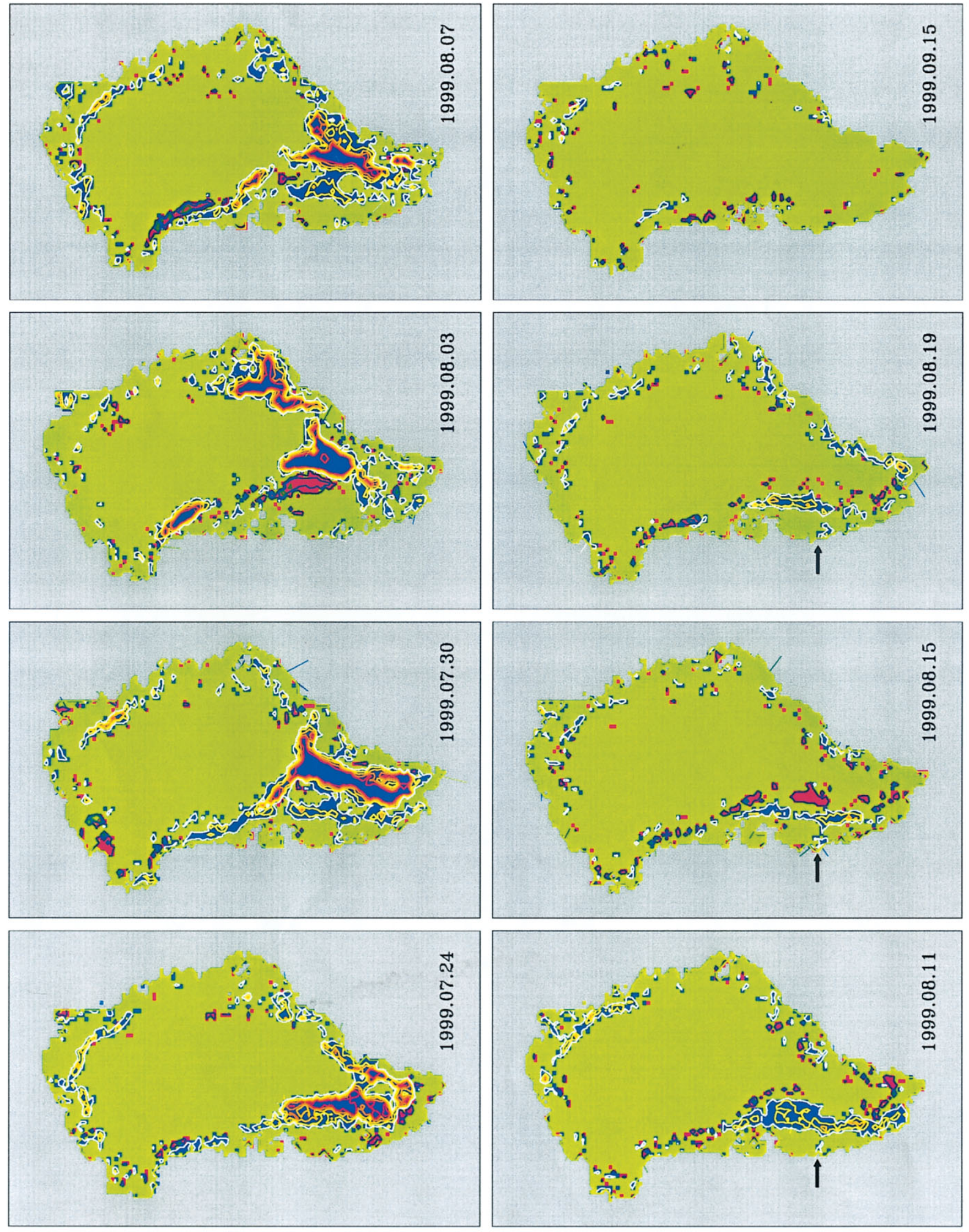

Fig. 5. Time-series images of melt regions on the Greenland ice sheet.

west flank of the Greenland ice sheet. Minimal melt activity occurs in September and later into the fall season. We compare the melt variations in Figure 5, derived from the satellite scatterometer, with in situ temperatures measured at several GC-Net stations shown in Figure 4, especially at times when the station data indicate warm conditions.

At Dye-2, temperatures (Fig. 4a) are above freezing and cooler in the morning of 24 July, closer to freezing on 30
July, warmer in the morning on 3 August, closer to freezing again on 7 August, and below freezing on the other dates. Dye-2 temperature records agree with the satellite timeseries results showing Dye-2 station in the middle of the blue melt region on 24 July, at the melt edge on 30 July, at the south tip of the red melt region on 3 August, and at the melt edge again on 7 August 1999. On the other dates (Fig. 5), Dye-2 is either at the edge or in the dry region, except on 

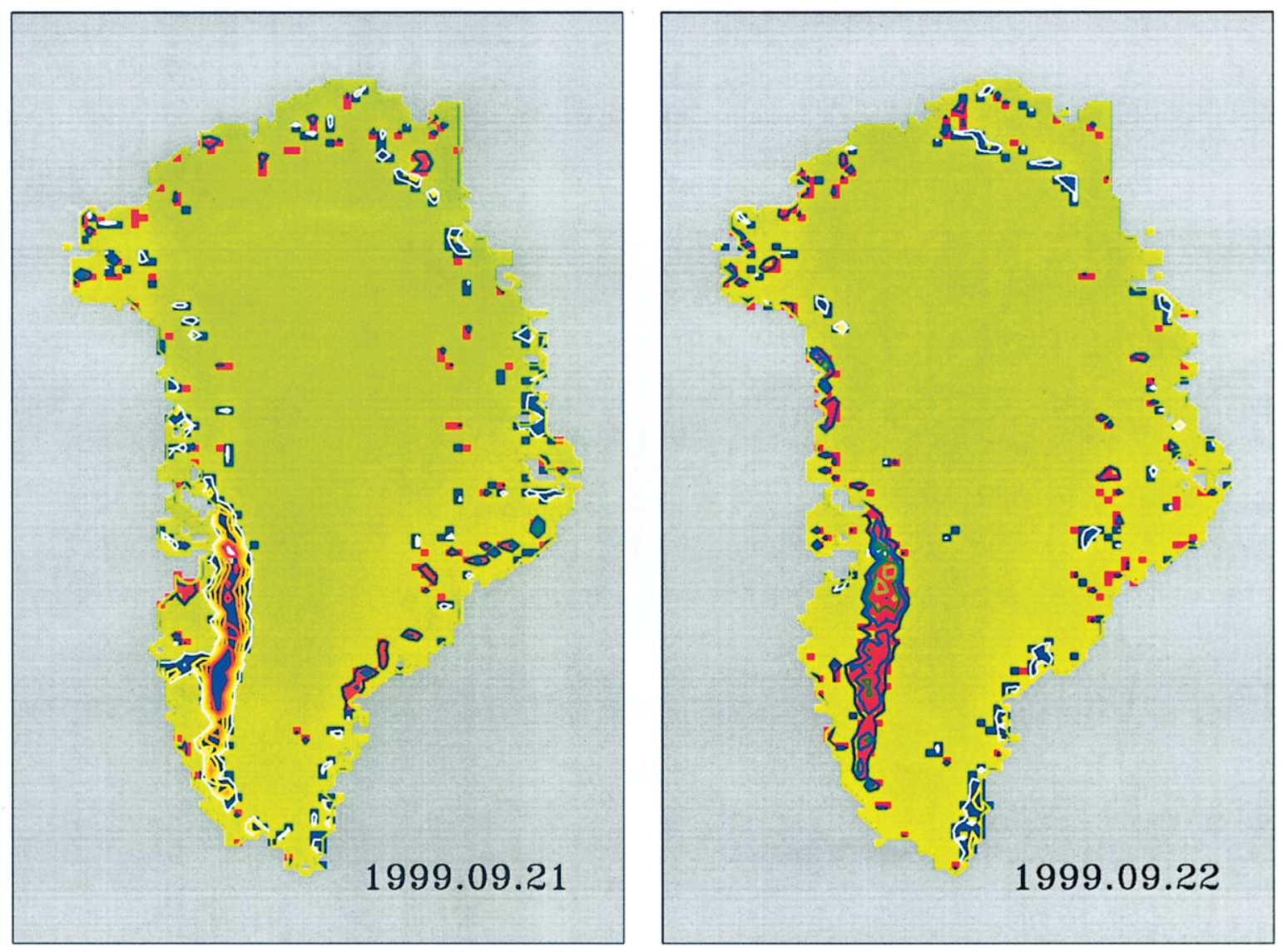

Fig. 6. Images of melt regions corresponding to an anomalous warming event in September 1999.

15 August when it is in the small red melt area. In this peculiar case, the hourly mean temperature at Dye- 2 is $2^{\circ} \mathrm{C}$ below freezing; however, wind speeds measured at Dye-2 showed a strong three-fold increase from about $4 \mathrm{~m} \mathrm{~s}^{-1}$ to $12 \mathrm{~m} \mathrm{~s}^{-1}$ from morning to afternoon.

At Crawford Point 1, the air temperature (Fig. 4c) on 24 July increases markedly from the cold condition in the morning to above freezing in the afternoon. At the time, the melt region extends from Dye-2 up to Crawford Point 1. For the other dates in July-August, Crawford Point 1 temperatures are at or below freezing and the station is at the melt edge or in the dry region. An interesting case in the time-series results at KAR station is on 3 August when the temperature (Fig. 4d) is high, corresponding to the significant melt region in the east on the Greenland ice sheet. At South Dome, the temperature (Fig. 4b) peaks a little above freezing on 30 July, when the contours in the map indicate minimal melt at the station surrounded by strong backscatter changes. Otherwise, the image series shows mostly dry condition at South Dome.

The melt patterns in the time series also exhibit recurrences that are related to physical characteristics of the ice sheet. The arrows marked on the maps of 11,15 and 19 August point to a recurring feature extending to the west from the internal melt region on the ice sheet toward the shoreline on the west coast. This feature coincides with the Sukkertoppen Iskappe west of the main ice sheet. This is a demonstration of the resolution of the QuikSCAT/SeaWinds data that is sufficient to pick up the melt features even on the smaller ice caps surrounding the ice sheet.

\subsection{September 1999 warming event}

In September, air temperatures are usually below freezing, and no significant melt area is detected. However, the scatterometer clearly delineates an extensive melt band on 21 and 22 September 1999. This is located along the west flank of the southern Greenland ice sheet as presented in Figure 6. Moreover, the melt region appeared in blue on 21 September, which indicates more wetness in the afternoon as seen in the left map in Figure 6. On the next day, the same melt region turned red, suggesting less wetness in the afternoon, as observed in the right map in Figure 6.

This melt band extends to the north over ETH/CU station, providing in situ data for air temperature, wind speed, shortwave solar radiation and net radiation (Fig. 7). On 21 September, the air temperature rose in the afternoon due to low-level clouds (solar radiation decreased) and due to a strong increase in wind speed. The wind increase is responsible for mixing warm air from the inversion at the top of the planetary boundary layer to the surface. This phenomenon has been discussed recently by Steffen and others (1999). The net radiation became positive at mid-day on 21 September. The warming effect results in the surface melt in the afternoon.

On 22 September, low-level clouds had moved out of the area and were replaced by thick medium-level clouds (Altos type), which can be seen in the low solar-radiation values. Wind dropped quickly to near-calm condition, with the minimum wind below $1 \mathrm{~m} \mathrm{~s}^{-1}$ just after noon. The temperature plot in Figure 7 shows a decreasing trend from the early morning into the late night. The net radiation decreased to a minimum at about the same time as the wind minimum, as evident in the corresponding plot in Figure 7. The satellite scatterometer image on 22 September still shows a wet surface in the morning and freezing in the afternoon. This case demonstrates that the temporal resolution of the SeaWinds scatterometer is sufficient to capture the short time-scale of weather events. 

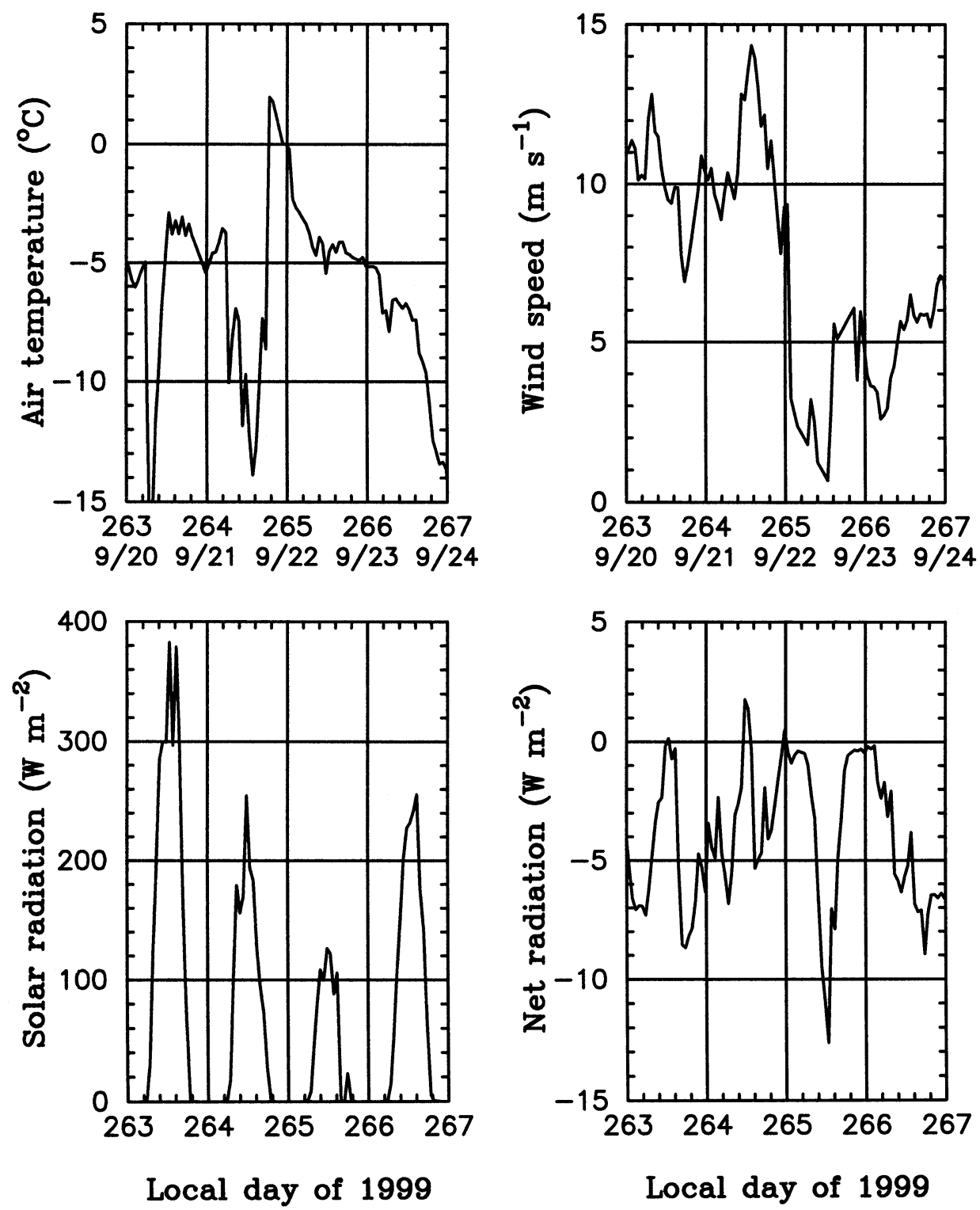

Fig. 7. In situ meteorological and radiation measurements at ETH/CUduring the time period of an anomalous warming event in September 1999.

\section{GONGLUSIONS}

Diurnal variations of melt regions on the Greenland ice sheet are studied from the summer melt to the fall freeze-up in 1999. Changes of melt regions are delineated daily with relative backscatter differences between morning and afternoon measured by the SeaWinds scatterometer on the QuikSCAT satellite. Satellite melt-mapping results are verified with in situ measurements from several GG-Net stations. Time-series melt images reveal melt regions and their patterns during the summer season. The wetness distribution patterns are shown to correlate with the topography of the Greenland ice sheet. Melt features are identified over the Sukkertoppen Iskappe west of the main ice sheet. An anomalous short-term warming event is detected on 21-22 September 1999. While the relative backscatter difference is consistent in the monitoring of melt regions, absolute backscatter subject to a stable calibration can also give further information on the conditions of the ice-sheet surface.

Previous analysis of snowmelt using passive-microwave satellite data from SSM/I by Mote and others (1993) and Abdalati and Steffen (1995) showed a similar melt pattern and a similar anomalous melting event found in June.
Nevertheless, active backscatter is due to electromagnetic wave scattering, and passive brightness temperature is sensitive to emissivity and physical temperature (Tsang and others, 1985). Therefore, combining active scatterometer and passive radiometer such as SSM/I can provide complementary information for studying Greenland melt regions. Such a combination requires co-registered data from different satellites, results of which will be presented in a future paper. More field experiments are also necessary in order to obtain quantitative wetness distribution over the melt regions from the satellite data.

\section{ACKNOWLEDGEMENTS}

The research described in this paper was carried out by the Jet Propulsion Laboratory (JPL), under a contract with the U.S. National Aeronautics and Space Administration (NASA). Partial support of the research is provided to S.V. Nghiem by the JPL Director's Research and Development Fund under the Lew Allen Award of Excellence. The research by the University of Colorado was supported by grants from the NASA Polar Program. The authors grate- 
fully acknowledge the careful reviews by two anonymous referees and especially the Scientific Editor, M. van den Broeke, who put in a considerable effort.

\section{REFERENGES}

Abdalati, W. and K. Steffen. 1995. Passive microwave-derived snowmelt regions on the Greenland ice sheet. Geophys. Res. Lett., 22(7), 787-790.

Abdalati, W. and K. Steffen. 1997. The apparent effects of the Mt. Pinatubo eruption on the Greenland ice-sheet melt extent. Geophys. Res. Lett., 24(14), 1795-1797.

Braithwaite, R.J., T. Konzelmann, C. Marty and O. B. Olesen. 1998. Reconnaissance study of glacier energy balance in North Greenland, 1993-94. F. Glaciol., 44(147), 239-247.

Denoth, A. 1985. Static dielectric constant as a textural index of snow. Ann. Glaciol., 6, 203-206.

Drewry, D. J., J. Turner and W. G. Rees. 1991. The contribution of Seasat to ice sheet glaciology. Int. F. Remote Sensing, 12(8), 1753-1774.

Fahnestock, M., R. Bindschadler, R. Kwok and K. Jezek. 1993. Greenland ice sheet surface properties and ice dynamics from ERS-1 SAR imagery. Science, 262(5139), 1530-1534.

Jezek, K. C., M. R. Drinkwater, J. P. Crawford, R. Bindschadler and R. Kwok. 1993. Analysis of synthetic aperture radar data collected over the southwestern Greenland ice sheet. 7. Glaciol., 39(131), 119-132.

Jezek, K. C., P. Gogineni and M. Shanableh. 1994. Radar measurements of melt zones on the Greenland ice sheet. Geophys. Res. Lett., 21(1), 33-36.

Konzelmann, T. and A. Ohmura. 1995. Radiative fluxes and their impact on the energy balance of the Greenland ice sheet. F. Glaciol., 41(139), 490-502.

Long, D. G. and M. R. Drinkwater. 1999. Cryosphere applications of NSCAT data. IEEE Trans. Geosci. Remote Sensing, GE-37(3), 1671-1684.

Mote, T. L. and C. M. Rowe. 1996. A comparison of microwave radiometric data and modeled snowpack conditions for Dye 2, Greenland. Meteorol. Atmos. Phys., 59, 245-255.

Mote, T. L., M. R. Anderson, K. C. Kuivinen and C. M. Rowe. 1993. Passive microwave-derived spatial and temporal variations of summer melt on the Greenland ice sheet. Ann. Glaciol., 17, 233-238.

Nghiem, S.V. and W.-Y. Tsai. 2001. Global snow cover monitoring with spaceborne Ku-band scatterometer. IEEE Trans. Geosci. Remote Sensing, 39(10), 2118-2134.

Nghiem, S.V. and 6 others. 1995. Polarimetric scattering from layered media with multiple species of scatters. Radio Science, 30(4), 835-852.

Ohmura, A., M. Wild and L. Bengtsson. 1996. A possible change in mass balance of Greenland and Antarctic ice sheets in the coming century. f. Climate, 9(9), 2124-2135.

Partington, K. C. 1998. Discrimination of glacier facies using multi-temporal SAR data. 7. Glaciol., 44(146), 42-53.

Steffen, K. 1995. Surface energy exchange at the equilibrium line on the Greenland ice sheet during onset of melt. Ann. Glaciol., 21, 13-18.

Steffen, K. and J.E. Box. In press. Surface climatology of the Greenland ice sheet: Greenland climate network 1995-1999. 7. Geophys. Res.

Steffen, K., W. Abdalati and J. Stroeve. 1993. Climate sensitivity studies of the Greenland ice sheet using satellite AVHRR, SMMR, SSM/I and in situ data. Meteorol. Atmos. Phys., 51, 239-258.

Steffen, K., W. Abdalati and I. Sherjal. 1999. Faceted crystal formation in the northeast Greenland low-accumulation region. f. Glaciol., 45(149), 63-68.

Stiles, W. H. and F. T. Ulaby. 1980. The active and passive microwave response to snow parameters. 1. Wetness. 7. Geophys. Res., 85(C2), 1037-1044.

Stroeve, J., A. Nolin and K. Steffen. 1997. Comparison of AVHRR-derived and in situ surface albedo over the Greenland ice sheet. Remote Sensing Environ., 62(3), 262-276.

Tiuri, M. T., A. H. Sihvola, E. G. Nyfors and M. T. Hallikainen. 1984. The complex dielectric constant of snow at microwave frequencies. IEEE $\mathcal{J}$. Oceanic Eng., OE-9(5), 377-382.

Tsai, W.-Y., S.V. Nghiem, J. N. Huddleston, M.W. Spencer, B.W. Stiles and R. D. West. 2000. Polarimetric scatterometery: a promising technique for improving ocean surface wind measurements. IEEE Trans. Geosci. Remote Sensing, GE-38(4), 1903-1921.

Tsang, L., J. A. Kong and R. T. Shin. 1985. Theory of microwave remote sensing. New York, John Wiley.

Vant, M. R., R. O. Ramseier and V. Makios. 1978. The complex-dielectric constant of sea ice at frequencies in the range $0.1-40 \mathrm{GHz}$. F. Appl. Phys., 49 (3), Part 1, 1264-1280.

MS received 20 June 2000 and accepted in revised form 24 July 2001 